\title{
COMPARISON OF THE SUCCESS OF EXTRACORPOREAL SHOCK WAVE LITHOTRIPSY (ESWL) WITH AND WITHOUT DJ STENTING IN PROXIMAL URETERIC STONE
}

\author{
Mudassar Saeed Pansota ${ }^{a}$, Sharmeen Shafqat ${ }^{\mathrm{b}}$, Shafqat Ali Tabassum ${ }^{c}$, Mumtaz Rasool ${ }^{\mathrm{d}}$, Muhammad Shahzad \\ Saleem ${ }^{e}$ \\ ${ }^{a}$ Assistant Professor, Department of Urology, Shahida Islam Medical College, Lodhran. \\ 'House officer, Department of Urology and Renal Transplantation, Bahawal Victoria Hospital/Quaid-e-Azam \\ Medical College, Bahawalpur. \\ 'Head Department of Urology and Renal Transplantation, Bahawal Victoria Hospital/Quaid-e-Azam Medical \\ College, Bahawalpur. \\ ${ }^{\mathrm{d}}$ Associate Professor, Department of Urology and Renal Transplantation, Bahawal Victoria Hospital/Quaid-e- \\ Azam Medical College, Bahawalpur. \\ ${ }^{\mathrm{e} A s s i s t a n t ~ P r o f e s s o r, ~ D e p a r t m e n t ~ o f ~ U r o l o g y ~ a n d ~ R e n a l ~ T r a n s p l a n t a t i o n, ~ B a h a w a l ~ V i c t o r i a ~ H o s p i t a l / Q u a i d-e-~}$ \\ Azam Medical College, Bahawalpur.
}

\begin{abstract}
:
BACKGROUND \& OBJECTIVE: There is disagreement in the use of ureteral double-] stent before the extracorporeal shock wave lithotripsy (ESWL), although most of the urologists suggest using stent in shock wave lithotripsy technique for stones bigger than $20 \mathrm{~mm}$, for preventing the risk of developing steinstrasse. To compare the success of ESWL with and without DJ stenting in proximal ureteric stone.

METHODOLOGY: A total of 60 patients form both genders, between 15 to 55 years of age, with a single proximal ureteric stone, were included. Patients with solitary functioning kidney, multiple stones, pregnancy, pyonephrosis and sepsis were excluded. In Group-A, ESWL without DJ stenting was completed while in Group-B, ESWL with DJ stent placement was done. In all patients, at least 4 sessions were done fortnightly. Patients were followed regularly and final success was noted after one month of completion of ESWL sessions.

RESULTS: The mean age was $36.85 \pm 8.61$ years. From 60 patients, $29(48.33 \%)$ were men and $31\left(51.67 \%\right.$ ) were women. Mean body mass index (BMI) was $28.30 \pm 2.20 \mathrm{~kg} / \mathrm{m}^{2}$. The average size of the stone was $12.47 \pm 2.57 \mathrm{~mm}$. Success (according to stone removal) of Group-A (ESWL without DJS) was seen in $26(86.67 \%)$ patients while in Group-B (ESWL with DJS) was seen in 16 $(53.33 \%)$ patients with $\mathrm{P}$-value of 0.005 .

CONCLUSION: This study concluded that success (in terms of stone clearance) of extracorporeal shock wave lithotripsy (ESWL) without DJ stenting is higher compared to with DJ stenting in upper ureteric stone.

KEYWORDS: Extracorporeal shock wave lithotripsy, Proximal ureteric stone, Stone clearance, DJ stent.
\end{abstract}

\section{How to cite this:}

doi: https://doi.org/10.37723/jumdc.v11i2.303

Pansota MS, Shafqat S, Tabassum SA, Rasool M, Saleem MS. COMPARISON OF THE SUCCESS OF EXTRACORPOREAL SHOCK WAVE LITHOTRIPSY (ESWL) WITH AND WITHOUT DJ STENTING IN PROXIMAL URETERIC STONE. jumdc. 2020;11(2):21-26.

doi: https://doi.org/10.37723/jumdc.v11i2.303

This is an Open Access article distributed under the terms of the Creative Commons Attribution License (http://creativecommons.org/licenses/by/4.0), which permits unrestricted use, distribution, and reproduction in any medium, provided the original work is properly cited. 


\section{INTRODUCTION:}

For curing the renal stones, the development of extracorporeal shock wave lithotripsy (ESWL) by Chaussy et al. in 1980 was a big revolution of the century ${ }^{[1]}$. Medication of urinary lithiasis has been altered by using shock waves ${ }^{[2]}$. Shock wave lithotripsy became quick to acknowledge as least invasive, a pretentious technique for most of the stones, but the drawback of this treatment was revealed. A medication of ureteric calculi depends upon a lot of factors like size, location at which they are present, the chemical composition of stones, and linked structural and anatomical abnormality ${ }^{[3]}$. Extracorporeal shock wave lithotripsy (ESWL), less invasive in the medical techniques of removing the stones, uses underwater energy waves on the stones that break them into passable material. Mostly, its use for stones having a size less than $2 \mathrm{~cm}$ is good ${ }^{[4]}$.

There is disagreement in the use of ureteral double-J stent before the extracorporeal shock wave lithotripsy, although all of the urologists suggest using stent in shock wave lithotripsy technique for stone bigger than $20 \mathrm{~mm}$, for preventing the risk of developing steinstrasse ${ }^{[5]}$. The reason for using a ureteral double-J stent before to ESWL is the fear of blocking the ureter at the time of passing broken stones ${ }^{[6]}$. A controversial outcome has been calculated by the studies on the impact of double J stent on the ESWL success rate. Also, treatment challenge has been posed by lumber ureteral stones; the impact of the existence of double J stent has not been the target of study ${ }^{[6-8]}$. In a study, the success of ESWL depending upon the stone removal in group 1 (with no DJS placement) and group 2 (with DJS placement) was $80.5 \%$ and $48.1 \%$, collectively ${ }^{[8]}$.

Using prophylactic double $\mathrm{J}$ stent placement in ESWL is a conflicting issue and also no study is conducted before on this topic. The rationale of this study was to compare the success of ESWL with and without DJ stenting in proximal ureteric stone. It can be evaluated that either DJ stent placement has any beneficial role during extracorporeal shock wave lithotripsy or just an economic burden on the patients. And if no extra benefit of its use can be found then their routine use can be minimized and encouraged in selected cases only.

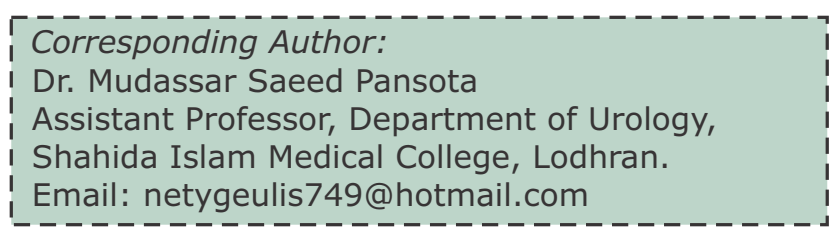

\section{METHODOLOGY:}

A complete randomized study was performed at the outpatient Department of Urology, Bahawal Victoria Hospital, Bahawalpur, and Shahida Islam Teaching Hospital, Lodhran from $1^{\text {st }}$ April 2018 to $31^{\text {st }}$ March 2019. The study has been approved by the ethical review committee of Quaid-i-Azam Medical College, Bahawal Victoria Hospital, Bahawalpur. Sample of 60 patients was collected by using a simple random sampling method. Inclusion criteria were patients age $15-55$ years presented with single proximal ureteric stone of size $\leq 20 \mathrm{~mm}$. Patients with multiple stones, pregnancy, solitary functioning kidney, bleeding disorder, pyonephrosis and sepsis, tightly impacted stone, and ureteral obstruction distal to stone were not included.

Patients were allowed to pick up the slip from the mixed slips [that composed of half A letter and half $B$ letter] and the individuals were placed in the selected group.

In Group-A, ESWL without DJ stenting was done while in Group-B, ESWL with DJ stent placement was done. All techniques were completed by one surgeon (at least 3 years of post-fellowship experience). Pre-operative antibiotics and analgesics were given to all patients. In all patients, at least 4 sessions were done fortnightly. Patients were followed regularly and final success (there was $100 \%$ clearance of stone, there was no stone [radio-opaque shadow] present on $x$-ray KUB and ultrasonography [acoustic shadow] after 1 month of ESWL) was noted after one-month completion of ESWL sessions.

Statistical analysis was performed using software SPSS 23. Mean and S.D were calculated for age, BMI, and size of the stone. Frequency and percentage were calculated for gender, residual stone (yes/no), and success (yes/no). The success of the two study groups was compared by chi- square test and P-value $\leq 0.05$ was considered as significant. 


\section{RESULTS}

The range of age in the study was from 15-55 years with an average age of $36.85 \pm 8.61$ years. Mean \pm S.D age of patients in category $A$, was $36.47 \pm 8.38$ years and in category $B$ was $37.23 \pm 8.95$ years. Most of the patients 32 $(53.3 \%)$ had an age between 36 to 55 years of age as represented in (Table-I).

From the 60 patients, $29(48.33 \%)$ were men and $31(51.67 \%)$ were women. The average BMI was $28.30 \pm 2.20 \mathrm{~kg} / \mathrm{m}^{2}$.
The size of stone in different categories is shown in (Table-II). The average size of the stone was $12.47 \pm 2.57 \mathrm{~mm}$.

Success (in terms of stone clearance) of GroupA (ESWL without DJS) was seen in $26(86.67 \%)$ patients while in Group-B (ESWL with DJS) was seen in $16(53.33 \%)$ patients with a P-value of 0.005 which is significant. It's mean there is an association between success of ESWL with and without DJ stenting in proximal ureteric stone as presented in (Table-III).

Table-I: Age distribution for both groups $(n=60)$.

\begin{tabular}{|c|c|c|c|}
\hline Age (years) & Category - $A(n=30)$ & Category -B $(n=30)$ & Total $(n=60)$ \\
\hline $\begin{array}{c}15-35 \\
\text { Frequency (\%) }\end{array}$ & $15(50.0)$ & $13(43.33)$ & $28(46.67)$ \\
\hline $\begin{array}{c}36-55 \\
\text { Frequency }(\%)\end{array}$ & $15(50.0)$ & $17(56.67)$ & $32(53.33)$ \\
\hline Mean \pm SD & $36.47 \pm 8.38$ & $37.23 \pm 8.95$ & $36.85 \pm 8.61$ \\
\hline
\end{tabular}

Table-II: Distribution of patients according to size of stone.

\begin{tabular}{|c|c|c|c|}
\hline $\begin{array}{c}\text { Size of stone (in } \\
\mathbf{m m})\end{array}$ & $\begin{array}{c}\text { Category -A } \\
(\mathbf{n = 3 0}\end{array}$ & Category -B $(\mathbf{n = 3 0})$ & Total $(\mathbf{n = 6 0})$ \\
\hline $\begin{array}{c}\mathbf{1 0} \mathbf{~ m m} \\
\text { Frequency (\%) }\end{array}$ & $06(20.0)$ & $04(13.33)$ & $10(16.67)$ \\
\hline $\begin{array}{c}\mathbf{1 1 - 2 0} \mathbf{~ m m} \\
\text { Frequency (\%) }\end{array}$ & $24(80.0)$ & $26(86.67)$ & $50(83.33)$ \\
\hline Mean \pm SD & $12.03 \pm 2.46$ & $12.90 \pm 2.66$ & $12.47 \pm 2.57$ \\
\hline
\end{tabular}

Table-III: Success of ESWL with and without DJ stenting in proximal ureteric stone.

\begin{tabular}{|c|c|c|c|c|c|}
\hline \multicolumn{2}{|c|}{} & Group-A (n=30) & Group-B (n=30) & Chi square \\
\cline { 3 - 4 } & Frequency (\%) & Frequency (\%) & Palue & \\
\hline \multirow{3}{*}{ Success } & Yes & $26(86.67)$ & $16(53.33)$ & 7.94 & 0.005 \\
\cline { 2 - 4 } & No & $04(13.33)$ & $14(46.67)$ & & \\
\hline
\end{tabular}

\section{DISCUSSION:}

It is contradictory to insert the DJ stent during ESWL of renal calculi. The conventional reason was using the ureteral stents for reducing the problems after ESWL and contributed to the good passage of the stone. But it was reported the problems that are characteristics of indwelling ureteral stent and it was concluded that stents cannot decrease post-ESWL problems they are linked with death and they cannot improve the passage of stones remarkably ${ }^{[9-11]}$. I have conducted this study to a contrast the success rate of ESWL with and without DJ stenting in proximal ureteric stone.

The age range in the research was from 15-55 years with the average age of $36.85 \pm 8.61$ years. The average age of the patient in category A was $36.47 \pm 8.38$ years and in category, B was $37.23 \pm 8.95$ years. Most of the 
patients 32 (53.33\%) were between 36 to 55 years. These results are also quite similar to the results of Rasool $\mathrm{M}$ et al ${ }^{[12]}$ and Sharma R et al ${ }^{[10]}$ who have shown mean age of $38 \& 39$ years respectively in their studies. Similarly, Manan A et al $^{[13]}$ has also shown a mean age of 38 years in his study. But on the other hand, a study found a much larger average age of 43 years compared to our study and other publications ${ }^{[14]}$. The majority of patients in our study were between 36 to 55 years of age. These findings are also quite similar to many existing studies ${ }^{[12-15]}$. Out of 60 patients, $29(48.33 \%)$ were males and $31(51.67 \%)$ were women. This female predominance was also seen in many previous studies ${ }^{[12-14]}$. So, this study presented that most of the patients with ureteric stones presented were in the $3^{\text {rd }}$ and $4^{\text {th }}$ decades of life with a female predominance.

Success (in terms of stone clearance) of GroupA (ESWL without DJS) was seen in $26(86.67 \%)$ patients while in Group-B (ESWL with DJS) was seen in $16(53.33 \%)$ patient with a P-value of 0.005 . In this research, the success of ESWL based upon stone removal in group 1 (without DJS placement) and 2 (with DJS placement) was $81.5 \%$ and $47.1 \%$, respectively $(P=0.017)$ ${ }^{[8]}$. Pace et al ${ }^{[15]}$ suggested that a $12 \%$ decrease of stone-free success rate can be caused by the existence of ureteral stent. Other authors ${ }^{[10,16-18]}$ have found same results that confirmed the existence of J stent caused no benefit on the results of ESWL, in reality, decreased its rate of success.

Depending upon the results of a study, the existence of a double DJ stent didn't impact the success rate of ESWL, the location of the stone in the ureter is of no concern. On the other hand, in a retrospective analysis, only $19 \%$ patient were fitted with a stent prior to treatment ${ }^{[18]}$. Accordingly, in another study, significant differences were not observed between the results of patients with stones that were treated with ESWL in the existence of double J Stents or in patients with no stent ${ }^{[19]}$.

In another study, the main factors that were pointed were a lumber situation, that was linked with a greater rate of success and existence of double DJ stent, that was linked with a low success rate $[80 \% \text { versus } 93 \%]^{[20]}$. Presently, urologist of European and American association recommended the presence of $D J$ stent prior to
ESWL for renal pelvic stones of $2 \mathrm{~cm}$ and more ${ }^{[21]}$. Excluding the patients with kidney failure and children, elaborated that DJ stenting before for $2 \mathrm{~cm}$ stone had no advantage in case of fever, stone removal, and NO. of ESWL session. However, ureteric colic was prominently less in stented groups. Infection in the lower urinary tract was prominently high in the patients having DJ stent. Expenses on the therapy were doubled in the stented group, thus stenting was not cost-effective technique ${ }^{[22]}$.

Thus, there is no benefit of stenting before the treatment over in-situ shock wave lithotripsy for ureteral calculi having a diameter of $2 \mathrm{~cm}$ or low that can cause medium or acute hydronephrosis. Some researchers have constricted using the DJ stents to stones bigger than $25 \mathrm{~mm}$ and some did not allow their use even for stone larger than $30 \mathrm{~mm}$ diameter ${ }^{[23]}$.

\section{CONCLUSION:}

This study concluded that success (in terms of stone removal) of ESWL without DJ stenting is higher compared to with DJ stenting in upper ureteric stone, so it is concluded that DJ stent placement has no beneficial role in patients undergoing ESWL for upper ureteric stone but just an economic burden. So, we recommend that routine use of DJ stent placement before ESWL should be minimized in every patient and encouraged only in selected and complicated cases only.

\section{CONFLICT OF INTEREST:}

All authors disclose no conflict of interest.

\section{GRANT SUPPORT\& FINANCIAL DISCLOSURES: None.}

\section{REFERENCES:}

1. Binu J, Vysakh R. Effect of stenting and non-stenting prior to extra corporeal shock wave lithotripsy of inferior calyceal stones: a comparative study. International Surgery Journal. 2016;3(1):226-229. Doi: 10.18203/2349-2902.isj20160231

2. Iqbal N, Assad S, Bhatti JR, Hasan A, Shabbir MU, Akhter S. Comparison of extracorporeal shock wave lithotripsy for 
urolithiasis between children and adults: a single centre study. Cureus. $2016 ; 8(9)$ : e810. Doi: 10.7759/cureus.810 PMID: 27800291

3. Khalique A, Arshad S, Kumar P, Hussain M. Frequency of stone clearance after extracorporeal shockwave lithotripsy for renal stones in adult patients with renal insufficiency. African Journal of Urology. $2017 ; 23(4)$. Doi:10.1016/j.afju. 2017.01.001

4. Aboutaleb H, Omar M, Salem S, Elshazly M. Management of upper ureteral stones exceeding $15 \mathrm{~mm}$ in diameter: shock wave lithotripsy versus semirigid ureteroscopy with holmium: yttrium-aluminum-garnet laser lithotripsy. SAGE open medicine. $2016 ; 4: 2050312116685180$. Doi: $10.1177 / 2050312116685180$

5. Sofimajidpour H, Rasti M, Gharibi F. The effect of a double-j stent in the treatment of kidney stones larger than $10 \mathrm{~mm}$ in children under 13 years, using extracorporeal shock wave lithotripsy (ESWL).

6. Obaid AT, Hussen RF. Role of double J stent in patients with renal stones undergo extracorporeal shock wave lithotripsy. Medical Journal of Babylon. 2012;9(3):629-642.

7. Pettenati $C$, El Fegoun $A B$, Hupertan $V$, Dominique S, Ravery V. Double J stent reduces the efficacy of extracorporeal shock wave lithotripsy in the treatment of lumbar ureteral stones. Central European journal of urology. 2013;66(3):309-313. Doi:10.5173/ceju.2013.03.art14 PMID: 24707370

8. Gültekin $M H$, Türegün FA, Ozkan $B$, Tülü $B$, Güleç GG, Tansu N, Demirdağ Ç, Kendigelen P, Erözenci A, Önal B. Does Previous Open Renal Stone Surgery Affect the Outcome of Extracorporeal Shockwave Lithotripsy Treatment in Adults with Renal Stones?. Journal of endourology. 2017 ;31(12):1295-300. Doil:10.1089/end. 2017.0473

9. Iqbal N, Malik $Y$, Nadeem $U$, Khalid $M$, Pirzada A, Majeed M, Malik HA, Akhter S. Comparison of ureteroscopic pneumatic lithotripsy and extracorporeal shock wave lithotripsy for the management of proximal ureteral stones: A single center experience. Turkish journal of urology. 2018;44(3):221-227. Doi: 10.5152/ tud.2018. 41848 PMID: 29733796

10. Sharma R, Choudhary A, Das RK, Basu S, Dey RK, Gupta R, Deb PP. Can a brief period of double J stenting improve the outcome of extracorporeal shock wave lithotripsy for renal calculi sized 1 to $2 \mathrm{~cm}$ ?. Investigative and Clinical Urology. 2017 ;58(2):103-108.

11. Damiano R, Oliva A, Esposito C, De Sio M, Autorino R, D'Armiento M. Early and late complications of double pigtail ureteral stent. Urologia internationalis. 2002;69(2):136-140.Doi:10.1159/ 000065563

12. Rasool M, Tabassum SA, Pansota MS, Mumtaz F, Saleem MS. Ureterorenoscopic Lithotripsy; Efficacy and Complications. Is Ureteric Stenting Necessary in Every Patient. Annals of Pakistan Institute of Medical Sciences. 2012;8(3):161-159.

13. Manan A, Anwar MS, Shah AA, Mahmood A, Tasneem RA. Efficacy of pneumatic lithoclast in the management of ureteric calculi. Esculapio. 2006;2(2):14-17.

14. Fong $\mathrm{YK}, \mathrm{Ho} \mathrm{SH}, \mathrm{Peh} \mathrm{OH}, \mathrm{Ng} \mathrm{FC}$, Lim PH, Quek PL, et al. Extracorporeal shockwave lithotripsy and intracorporeal lithotripsy for proximal ureteric calculi-a comparative assessment of efficacy and safety. AnnalsAcademy OF Medicine Singapore. 2004 ;33(1):80-83.

15. Pace KT, Weir MJ, Tariq N, Honey RJ. Low success rate of repeat shock wave lithotripsy for ureteral stones after failed initial treatment. The Journal of urology. 2000;164(6):1905-1907. Doi:10.1016/ S0022-5347(05)66914-5

16. Chang SC, Kuo HC, Hsu T. Extracorporeal shock wave lithotripsy for obstructed proximal ureteral stones. European urology. 1993;24:177-184.Doi:10.1159/ 000474290

17. Manu MK, Darsan S, Vasantharaja R. Clinical outcome of renal calculi patients undergoing extracorporeal shock wave lithotripsy with and without DJ stent. Journal of evidence based medicine and healthcare. 2019;6(38):2569-2573. Doi: $10.18410 / \mathrm{jebmh} / 2019 / 528$

18. Wang H, Man L, Li G, Huang G, Liu N, Wang 
J. Meta-analysis of stenting versus nonstenting for the treatment of ureteral stones. PloS one. 2017;12(1):e0167670. Doi:10.1371/journal.pone.0167670

19. Middela S, Papadopoulos G, Srirangam S, Rao P. Extracorporeal shock wave lithotripsy for ureteral stones: do decompression tubes matter?. Urology. 2010;76(4):821-825. Doi:10.1016/ j.urology.2010.01.051

20. Gomha MA, Sheir KZ, Showky S, AbdelKhalek M, Mokhtar AA, Madbouly K. Can we improve the prediction of stone-free status after extracorporeal shock wave lithotripsy for ureteral stones? A neural network or a statistical model?. The Journal of urology. 2004;172(1):175-179. Doi:10.1097/ 01.ju.0000128646.20349.27

21. European Association of Urology. Home page of European Association of Urology. Online: [Cited December 2011] Available from URL: http://www. uroweb. org. 2011:11-2.

22. Mohayuddin N, Malik HA, Hussain M, Tipu SA, Shehzad A, Hashmi A, et al. The outcome of extracorporeal shockwave lithotripsy for renal pelvic stone with and without JJ stent--a comparative study.
Journal of Pakistan Medical Association. 2009;59(3):143-146.

23. El-Assmy A, El-Nahas AR, Sheir KZ. Is preshock wave lithotripsy stenting necessary for ureteral stones with moderate or severe hydronephrosis?. The Journal of urology. 2006 Nov 1;176(5):2059-2062. Doi:10.1016/j.juro.2006.07.022

\section{Authors' Contribution:}

Mudassar Saeed Pansota: Study design and manuscript writing and proof reading.

Sharmeen Shafqat: Data collection, analysis and manuscript writing.

Shafqat Ali Tabassum: Data collection, statistical analysis and literature search.

Mumtaz Rasool: Data collection analysis and final draft of study.

Muhammad Shahzad Saleem: Manuscript writing and proof reading.

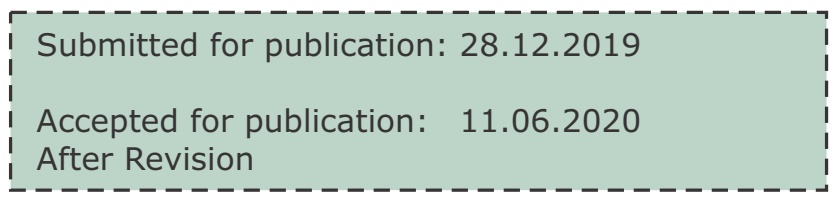

